\title{
A Review of Immune System Components, Cytokines, and Immunostimulants in Cultured Finfish Species
}

\author{
Timothy J. Bruce ${ }^{1 *}$, Michael L. Brown² \\ ${ }^{1}$ Missouri Department of Conservation, Lost Valley Hatchery, Warsaw, Missouri, USA \\ ${ }^{2}$ Department of Natural Resource Management, South Dakota State University, Brookings, South Dakota, USA \\ Email: ^3tjbruce3@gmail.com
}

How to cite this paper: Bruce, T.J. and Brown, M.L. (2017) A Review of Immune System Components, Cytokines, and Immuno-stimulants in Cultured Finfish Species. Open Journal of Animal Sciences, 7, 267-288. https://doi.org/10.4236/ojas.2017.73021

Received: March 1, 2017

Accepted: July 9, 2017

Published: July 12, 2017

Copyright @ 2017 by authors and Scientific Research Publishing Inc. This work is licensed under the Creative Commons Attribution International License (CC BY 4.0).

http://creativecommons.org/licenses/by/4.0/

\section{(c) (i) Open Access}

\begin{abstract}
Aquaculture is a rapidly growing global agriculture sector and the importance of fish health has become of upmost importance as production levels and stocking densities increase. Over the past few decades, there have been a large number of immunological investigations on commonly cultured finfish species. Further, new technologies and strategies that embody use of fish immunostimulants, probiotics, and vaccinology rely heavily upon a comprehensive understanding of teleost immune system mechanics. The teleost immune system works in concert to properly recognize, control, and clear aquatic pathogens. Recent findings have exemplified the cooperative efforts of the nonspecific and adaptive branches, and have put forth an emphasis on the importance of the mucosal immune response in all aspects of a mounted immune response. This review provides a generalized overview of the innate and adaptive arms of the fish immune system, and provides highlights of recently published work in the areas of signaling networks and mucosal immune interactions.
\end{abstract}

\section{Keywords}

Innate Immunity, Adaptive Immunity, Cytokines, Immunostimulation, Aquaculture

\section{Introduction}

Global aquaculture production has rapidly increased over the past few decades. Increasing world population size, standard of living, and globalization have created a large demand for the efficient production of high quality, protein-rich food. High quality protein acquired from fish and shellfish currently constitutes approximately 16 percent of the world's consumption of animal protein sources 
and aquaculture products are likely to be a primary food source for future generations [1]. The increasing amount of protein needed for the growing world population has placed excessive demands on the wild-capture fishing industry. Enlarged harvest rates impact the sustainability of wild stocks and have driven the growth of the aquaculture production sector. In 2014, global fisheries' production was estimated at 167 million.tonnes, with 73.8 million.tonnes of this amount credited to aquaculture production [2]. Further, global finfish culture produced 49.8 million.tonnes of fish, with an estimated first-sale marketable value of $\$ 99.2$ billion USD [2]. As the global aquaculture realm becomes reliant upon increased fish production, the risk of disease manifestation and large-scale production losses resulting from aquatic pathogens may provide vast economic complications for the industry and negatively impact producers and valuable fish inventories. For example, The World Bank recently reported an estimated $\$ 6$ billion (USD) in global aquaculture disease-related losses per year [3].

As commercial fish production (primarily teleost fishes) increases, both aquaculture producers and researchers have understood the importance of the understanding immune dynamics and composition. A thorough understanding of these teleost immune components may better elucidate novel production strategies for finfish culture, incorporating rapidly expanding areas of both fish health and nutrition. This has been demonstrated by recent reviews focusing on fish immune system topics as vaccine design, immunostimulant administration, nutrition, and interactions with growth mechanics [4] [5] [6] [7]. These complex research components of the teleost immune response can be generally divided into three elements: Inputs or stimuli, recognition by the immunological system, and response mechanisms (Figure 1). The aim of this review article is to discuss these integrated mechanics with respect to current, applied research aims in aquaculture. This current review provides a background and recent research highlights of the key components of the fish immune system, with respect to commonly cultured species, including rainbow trout (Oncorhynchus mykiss) and Atlantic salmon (Salmo salar).

\section{Teleost Innate Immunity}

Maintenance of the immune system within teleosts is essential to metabolism,

\begin{tabular}{|c|c|c|c|c|}
\hline $\begin{array}{l}\text { Environment } \\
\text { Pathogens } \\
\text { בे| Nutrition } \\
\text { ב्= Antimicrobials } \\
\text { Therapeutants } \\
\text { Vaccinations }\end{array}$ & 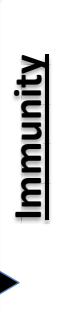 & $\begin{array}{l}\text { Innate } \\
\text { Adaptive } \\
\text { *Mucosal }\end{array}$ & 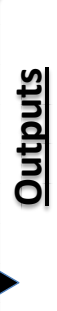 & $\begin{array}{l}\text { Pathogen } \\
\text { Clearance } \\
\text { Memory } \\
\text { Response } \\
\text { Gut Health } \\
\text { Regulatory }\end{array}$ \\
\hline
\end{tabular}

Figure 1. Inputs, immune components, and outputs of the teleost immune response. Teleost mucosal immunity contains components of both innate and adaptive immunity, but may be considered a subsidiary branch in some aspects. 
growth and physiological development. In aquaculture, broodstock health and expected yields hinges upon the fishes' abilities to protect themselves from external pathogenicity. To protect themselves from outside pathogens, teleosts have developed innate and marginally adaptive immune system components to combat many types of bacteria and viruses. The innate immune system directs nonspecific pathogen clearance through a variety of humoral and cellular responses [8]. The ability to eliminate foreign matter from an organism is dependent upon the capacity to recognize self versus non-self cells; a fundamental building block of immunology. Thus, the teleost immune system functions in a generalized capacity (the innate immune response) and a more complex defense (adaptive immunity) to resist a wide array of foreign materials.

The innate immune system includes many internal and external barriers, such as the skin and enclosed epithelial surfaces, to limit pathogen intrusion. The scales, mucous, and gastric environment all act in unison to effectively trap and expunge foreign microbes [8]. Further, cellular components exist within the plasma to combat organisms that have penetrated the epithelium. Phagocytic cells, including macrophages and granulocytes, monitor the interior spaces to aid in the inflammatory response and removal of bacterial components. Furthermore, nonspecific cytotoxic cells may direct microbial degradation via pattern recognition, and antigen-presenting cells (dendritic cells and macrophages) may transfer more specialized pathogenic components to the adaptive immune system [8]. The final component of the innate immune system involves the humoral response, where specialized plasma or epithelial components may diminish microbes through enzymatic degradation. These main constituents work in concert to prevent infections and they may overlap in function to optimize protection for teleosts.

The teleost epithelial barrier is composed of an integument covered externally with protective scales for environmental protection. In the case of some scaleless teleosts, this integumentary defenseis reliant solelyupon the composition of various cell and fiber types within the dermal and epidermal layers [9]. This barrier takes on an immunological role by separating the internal and external environments while secreting mucus and lysozyme to enhance the breakdown of microbes [10]. Depending upon the epithelial composition, some fish may experience an increase of external disease resistance while showing no difference in disease susceptibility following bacterial infection [11]. In general, mucus is a secretion of viscous glycoproteins and mucin that acts to lubricate the outer anatomical structures that enhance osmoregulation, encourage microbial removal, improve swimming ability by reducing resistance, and assist with respiration [10].

The concentration and secretion rates of fish mucus will change with environmental conditions and secretion also be induced by stressful situations. Additionally, the concentration of mucus secretion varies greatly among different fish species and may vary based on the bacterial contact with the apical surface of the epithelium [12]. 
Mucus has been determined to contain lysozyme, anti-bacterial peptides, proteases, and lectins to protect against microbes [12]. Antibacterial peptides, including pleurocidin, attack the cell wall A-layer components of invading bacteria and are predominately found on the skin and gastric linings of teleosts [11]. Lectins are proteins that bind to carbohydrates on bacteria to prevent further binding to the integument and target the cell for opsonization [13]. Opsonization is the molecular process of marking a target cell with complement components in an effort to further promote stronger phagocytosis of the cellular component or activate lymphocytes for more enhanced or advanced pathogen clearance [14]. Various types of lectins, such as C-lectin and galactose-binding lectin, serve different immunological functions (macrophage activation, respiratory burst, etc.) and many are $\mathrm{Ca}^{2+}$ dependent in their binding competencies [13]. Cathepsins and trypsin-like proteases function by lysing external bacteria cell walls [11]. These proteases target cell wall and membrane components in an effort to rupture the cell and inhibit infectivity. Lastly, lysozyme is a major enzyme that inhibits bacterial infection through the disruption of the $\beta-(1,4)$ glycosidic bonds of peptidoglycan within the bacterial cell wall [15]. Lysozyme also inhibits gramnegative bacteria and can be found in the mucus, plasma serum, and major organs of teleosts. It is produced by the macrophages and granulocytes; thus, it is found throughout vertebrate systems [16]. Lysozyme acts independently of the complement pathway for bacterial clearance and production increases following bacterial attachment or the acute phase of the teleost stress response [17]. These epithelial barrier components are vital to the prevention of bacterial entry into fishes. If these factors fail to eliminate pathogen entry, the cellular components of the innate immune system are the next line of defense for non-specific removal.

Cellular components of the non-specific immune system provide protection from pathogens that have breached the primary barriers. The two classifications of phagocytic cells are granulocytes and monocytes/macrophages. Granulocytes include neutrophils, basophils, and eosinophils, and are characterized by the presence of major granule components in the cytoplasm. The polymorphonuclear cells are important in phagocytosis of invasive bacteria and parasites. The head kidney (pronephros) is the major hematopoietic organ in teleosts and compares to the function of bone marrow in mammals [18]. It has been determined in a challenge study with Vibrio anguillarim that up to $85 \%$ of phagocytic cells in the pronephros may be acidophilic granulocytes [19]. This composition may change depending on the immunological status of the fish. Macrophages are phagocytic cells that serve to remove bacteria via phagocytosis and act as antigen-presenting cells (APCs) for the production of antigens in the adaptive immune response. Macrophages utilize cell-mediated exocytosis and the production of super oxide radicals via respiratory burst to eliminate pathogens in the teleost system [14]. Pathogen-associated molecular patterns (PAMPs) are foreign configurations that signal an invading cell to system macrophages [20]. The macrophages have pattern recognition receptors (PRRs) on their cell surfaces that allow for ligand binding to the specific PAMPs bound on incoming 
matter. This relationship that allows for the macrophages to function in a nonspecific manner to remove a cell deemed as "non-self." Following the connection of the bacteria to the macrophage, the macrophage then primes the respiratory burst and the production of reactive superoxide intermediates [20]. Various peroxides, peroxidases, nitric oxide derivatives, and chloramines are produced to attack the invading bacterium and slow the metabolism [14]. Various cytokines are employed to transmit directions to macrophages and direct effective phagocytosis. It has been hypothesized that IL- $1 \beta$ (Interleukin 1 beta) is responsible for phagocyte recruitment through the activation of chemoattractants and enhanced immune gene expression [21]. Additionally, macrophages also harness the ability to produce transferrin, a serum protein that is capable to binding excess iron from the plasma, in an effort to limit bacterial metabolism [20]. In addition to the granulocytes and macrophages, natural cytotoxic cells (Natural Killer, or NK, cells) exist for the non-specific removal of parasites, tumors, and cells that have been virally infected [14]. These cells are classified as agranular in nature, do not require the Major Histocompatibility Complex (MHC) class restrictions for removal, and are commonly located within the pronephros and spleen [22]. NK cells also contain a C-type lectin receptor for binding to class I marked cells and contain the ability to both stimulate and inhibit cytokine production in regards to removing the targeted cell [23]. Hence, NK cells may be thought of as independent of the other phagocytic cells and lymphocyte populations. There are various types of NK cells and their exact nonspecific defense mechanisms are still being explored to date. T-cytotoxic cells also exist to detect virally-infected cells, similar to the response of human CD8+ (Cluster of differentiation 8) $\mathrm{T}$ lymphocytes [22].

A major humoral defense mechanism in teleosts is the ability to remove bacteria and associated matter via the complement system. The complement system is partially conserved in many vertebrates and acts via the Classical, Alternate, and Lectin-mediated pathways [24]. These pathways differ in their initiation molecules, but all facilitate the activities of Complement Component 3 (C3). The Classical and Lectin pathways use Complement Component 4 (C4), Complement Component $1(\mathrm{C} 1)$, and Complement Component 2 (C2) analogues in conjunction with immunoglobulin fixation to direct the cascade while the Alternate pathway is stimulated from the binding of $\mathrm{C} 3$ to the surfaces of pathogens [25]. In the Lectin pathway, Mannose-binding Lectin (MBL) acts as a C1 homologue to cleave $\mathrm{C} 2$ and $\mathrm{C} 4$ counterparts upon membrane attachment, and may operate in the absence of $\mathrm{C} 1$ [24]. Furthermore, C3 is generated in an alternate pathway from the combination of Plasma Factor B and C3 $\left(\mathrm{H}_{2} \mathrm{O}\right)$ that continue the cycle [26]. Pentraxins, such as Complement Reactive Protein (CRP) and Serum Amyloid Protein (SAP), are involved with the lectin-binding mechanism for complement activation on the cell membranes [8]. In addition to the activation of teleost complement, CRP is also a powerful promoter of opsonization and can effectively aid in the removal of fungal invaders or parasites [27]. Within these pathways, the molecule C3 is the major component of the 
complement pathway and may cleave C3a or C3b subsets; C3a further promotes inflammatory responses while $\mathrm{C} 3 \mathrm{~b}$ may further facilitate phagocytosis with nearby cells or assist with cleaving C5 in an effort to further the cascade [24]. C5a is again used as a chemoattractant for phagocytic cells while C5b is an initiating factor in the formation of the membrane attack complex (MAC) [11]. C3 and $\mathrm{C} 5$ convertases are used to enhance the progression through the cascade and cleave new molecular subsets [28]. Ultimately, the complement exerts its' ability to extinguish pathogens by lysis with the MAC or targeting the cells for further removal via opsonization [14]. The complement pathway is an effective procedure for promptly facilitating a non-specific immune response in teleosts. The availability of specific teleost cytokines and enzymes orchestrate the progression of the innate immune system.

\section{Teleost Adaptive Immunity}

The conservation of many immunological components in the innate immune system of vertebrates also translates to the adaptive immune system of fish. The adaptive immune system provides a more specified approach for pathogen removal and is the secondary defense for the fish from the external environment. Adaptive immunity involves the incorporation of $\mathrm{T}$ (thymus) and B (bursa-derived) lymphocytes and the capability to conduct cell-mediated removals. More specifically, the specific response includes receptor interactions with $\mathrm{T}$ cell receptors, immunoglobulins, and antigen-presenting cells [29].

The teleost cell-mediated, cellular components serve the purpose of removing antigens based on their genetic code and recognition. B-cell lymphocytes are integral to the proper disposal of foreign matter and the humoral branch for cell-mediated removal. B-cells function by secreting immunoglobulins into the plasma to create an antigen-binding complex [30]. These secretory cells are analogues of the mammalian plasma cells and are known as antibody secreting cells (ASCs) or plasmablasts [31]. The largest concentration of B-lymphocytes exists in the pronephros and, accordingly, this region is also rich in immunoglobulins [32]. The incorporation of surface-bound immunoglobulins on the membrane of the B-cell is also naturally occurring and allows for further antigen interactions and subsequent pathogen removal or control. Following the creation of the antibody-antigen complex, the B-cell is capable of orchestrating phagocytic cells or the complement pathways for the removal of the target cell. This immunoglobulin, in conjunction with associated transmembrane proteins, constitutes the B-cell receptor complex [30]. The B-cell is responsible for the appropriate allocation of immunoglobulins in the plasma and BcR complex and can induce immunoglobulin characterization and class-switching through $\mathrm{V}(\mathrm{D}) \mathrm{J}$ recombination events [33]. The class-switching and genetic rearrangement of the immunoglobulins allows for an extremely specific antibody-antigen interaction and the flexibility to sort for future antigen encounters.

Immunoglobulins (Ig) contain heavy and light chain structures with respective constant and variable regions [31]. In teleosts, $\operatorname{IgM}, \operatorname{IgD}$, and $\operatorname{IgT}$ (associated 
with the intestinal immunology) have been determined as antibody classes [34]. $\operatorname{IgM}$ is the most prevalent teleost immunoglobulin and takes on a tetrameric form as an antibody, allowing for eight separate antigen binding sites (separated by disulfide bonds) [31]. IgM shares a similar multi-faceted formation with the mammalian form (pentameric), but in mammals, IgG is the most common immunoglobulin. IgM is commonly used in many immunoglobulin studies because it is most prevalent and the regions are well-mapped. IgM contains four constant regions of exons that constitute a conserved $\mu$ region [35]. It should also be noted that IgM may exist in a monomeric form, with the possibility of forming a tetrameric complex, within some teleost immune systems [29]. IgD in teleosts is a relatively new discovery and involves alternate splicing at the c- $\delta$ region [31]. IgD has been characterized and discovered in channel catfish (Ictalurus punctatus) and it appears that IgD tends to be placed on B-cell membranes, perhaps adding excess to the BCR [36]. The IgT has yet to be fully characterized and it is quite dissimilar to both IgM and IgD. It is speculated that IgT contributes a protective role in developed mucosal and gastrointestinal regions, but it has also been found to be present in zebrafish during early immunological development [37].

$\mathrm{T}$ cells take on an intrinsic role in the cell-mediated adaptive immune system and direct immune function following the initial nonspecific defenses and provide an immunological response following antigen recognition with APCs. Following pattern recognition through the TCR, the T cell may then direct the foreign matter to removal via cytokine stimulation, phagocytosis or eliminate the cell with its own intrinsic function. Thus, the two main classes of $\mathrm{T}$ cells, $\mathrm{T}$ helper cells and cytotoxic $\mathrm{T}$ cells, elicit their cellular response depending on the MHC pairing and specific antigen-receptor interactions [38]. The differentiation and regulation of $\mathrm{T}$ cells is dependent upon various influences from nearby immunological molecules. For instance, the helper $\mathrm{T}$ cells are regulated by antigen binding affinity, antigen concentrations, and signaling from APCs, while cytotoxic $\mathrm{T}$ cells are influenced by surrounding helper $\mathrm{T}$ cells and cytokine intensities [39]. Additionally, the release of IL-2 has been found to act as a growth promoter for overall $\mathrm{T}$ cell development [40]. Following differentiation, helper $\mathrm{T}$ cells release IFN- $\gamma$ to assist with combatting viral infections and also producelymphotoxin (LT) to assist with intracellular pathogens [40]. The classification of helper $\mathrm{T}$ cells can be further divided into classifications based on their functionality and targeted pathogens. The Th1 cell is responsible for providing cell-mediated clearance of microbes while the Th2 subset tends to target multifaceted pathogens, such as parasites [41].

Teleost $\mathrm{T}$ cells appear to be closely related to the mammalian subset and contain complementarity-determining region 3 (CD3) binding domains within the TCR [42]. The thymus and head kidney harbor T cell development and serve as a base for circulating $\mathrm{T}$ cells in the plasma. Koppang et al. (2010) have established the salmonid CD3 as an effective T cell marker to evaluate expression regions and anatomical distributions of T cells [42]. Consequently, the TCR $\beta$ re- 
gion has been found to undergo recombination and is immensely involved with viral recognition [43]. It was found that large populations of $\mathrm{T}$ cells inhabit the thymus, while they are also present in kidney and splenic regions following development [38]. In addition to $\mathrm{T}$ cell characterization, the antigen presentation of both major histocompatibility complex (MHC) class I and II has illustrated the directional activation of a $\mathrm{T}$ cell response. MHC class I interacts with the CD8+ cytotoxic T cells while MHC class II assists with complex formation in helper T cells [38].

\section{Teleost Intestinal Immunity}

The intestinal anatomy in teleosts provides antigen processing during digestion and enhances immune capacity. As external food sources enter the gastrointestinal tract (GIT) following feed uptake, the stomach and intestinal segments are essential to the removal of pathogenic material in an effort to conserve homeostasis. The intestinal region contains some structural similarity to the mammalian anatomical design and allows for an added degree of protection from ingested, pathogenic materials. According to Rombout et al. (2011), the teleost intestinal immune components contain both effector and inductor sites, which express a wide variety of functions [44]. The effector sites contain the gut-associated lymphoid tissues (GALT), such as Peyer's patches, while the inductor sites are constituted by the lamina propria and its intrinsic lymphocyte population. This combination of lymphocytes and immunoglobulins work in concert to provide an encompassing protection throughout the distal intestine. Additionally, there is a substantial population of T-lymphocytes (both $\mathrm{CD} 8^{+}$and $\mathrm{CD} 4^{+}$), B-cells (as indicated by the presence of IgT), and cytokines to create a diversified immunological center [45]. This dynamic assortment of immunological cells allows for enhanced antigenic uptake, swift clearance, and the ability to elicit a systemic immune response.

Components of teleost gut immunology have been closely examined as we further develop our understanding of the integral relationship between fish health and nutrition. As aquaculture production numbers rise, the exploration for high performance alternative feedstuffs has become a major focus area. Soy protein has been a forerunner in the plant protein realm of fishmeal replacement, and offers a high protein substitute at an attractive price point [46]. In the past, there has been a focus on the intestinal enteritis associated with the administration of soybean meal-based diets, particularly in salmonids. The distal intestine is most susceptible to enteric inflammation as a result of the inclusive antinutritional factors (ANFs) and alcohol soluble components of the feed ingredients [47]. Enteropathy may be characterized by decreased vacuoles counts and altered morphology, increased leukocyte prevalence, decreased microvilli density, and a broadening of the lamina propria [48]. Furthermore, it has been found that a soybean meal inclusion of $5 \%-10 \%$ may create some symptoms of enteritis in salmonids, necessitating the need for further feedstuff processing [48].

Advanced bioprocessing and extrusion technology provides for the elimina- 
tion of these enteritis-causing factors and has the use of soyin aquafeed manufacturing. Interestingly, Urn et al. (2008) found that a slight increase of $4^{\circ} \mathrm{C}$ in water temperature may also induce the rapid onset of enteritis following consumption of soybean diets by Atlantic salmon (Salmo salar) [49]. In another study with European sea bass (Dicentrarchus labrax), Torrecillas et al. (2013) found that treatment with mannan oligosaccharides increased leukocytes, goblet cells, and lymphocyte migration, thereby indicating a pronounced immunological benefit from a natural feed additive [50]. The additional bioprocessing of these feedstuffs is responsible for reducing ANF effects and the enhanced digestibility.

The teleost intestine contains many of the innate immune attributes found in other anatomical regions. The intestinal mucosa is a saturated substrate for leukocytes and they are harbored within layers of the lamina propria [51]. Within these strata are NK cells, lysozyme, and granulocyte proliferation; ultimately leading to increased production of superoxides and lysozyme [52] [53]. In an additional role, the epithelial cells act as a secondary barrier to secure the passage while allowing for appropriate nutrient passages, signaling permeability and a viable gut microflora to enhance digestive processes [50]. Macrophages in the distal portions of the intestine also aid as antigen-presenting cells, thereby allowing for antigens to interact with the adaptive immune system for recognition. In addition to the resident macrophages, other granulocytes are also found in the intestinal segments for innate clearance [51]. These innate populations are spread throughout the lamina propria and epithelial linings of the intestine, which allow for a close proximity to digested pathogens.

The adaptive immunity of the teleost gut has been well-studied; yet, many avenues remain to be explored. The lack of an organized GALT and varying $\mathrm{pH}$ changes through GIT passage allow for a diverse habitat of immune cells [34]. The intestinal regions have been found to have an inherent population of immunoglobulins and isolated populations of both B and T cells, known and intra-epithelial lymphocytes (IELs) [54]. Additionally, T cells have been found to be present in the midgut, harbored in the lamina propria. These $\mathrm{T}$ cells can be further divided into regulator and effector populations in order to examine the adaptive response [55]. Immunoglobulins have been thought to be dispersed throughout various intestinal regions; yet, it has been concluded that there are some relatively localized segments that are rich in IgM. Following viral interference, mast-cell analogues have been determined to assist with inflammation and the indirect propagation of immunoglobulins [56]. Inami et al. (2009) found that there is a higher concentration of IgM-positive cells in the rectal region of Atlantic cod (Gadus morhua), in comparison to the foregut and stomach regions [57]. This finding coincides with the known adaptive immunocompetency of the distal intestine, and elaborates on the ability for immunoglobulins to aggregate in specified regions aside from traditional GALT. In terms of antigen presentation to the adaptive components, the distal to mid intestinal regions have been found to contain the greatest concentrations of MHCII molecules, and subse- 
quently, lymphocyte pockets and dendritic cells [58].

Adaptive immune studies of the intestine have also created some speculation on additional immunoglobulins within the teleost system. ILs, insulin-like growth factors (IGFs), and COX genes have all been determined to play an essential role in cytokine signaling within intestinal layers [52]. As fish lack IgA, a serum or secretory immunoglobulin involved in mammalian mucosal systems, IgM is rapidly degraded within the harsh environment [59]. Thus, the need for a rapidimmunoglobulin proliferation response and adequate cytokine signaling is integral to ensure a prominent internal defense. Ordas et al. (2012) studied the CCR7 receptor for cytokine activation and regulation [60]. It was determined that this receptor recognized cytokine motifs and assists with the up-regulation of $\mathrm{B}$ and $\mathrm{T}$ cells within the teleost gut. A comprehensive determination of the role of intestinal cytokines will elucidate the mechanism of viral and parasitic invasions among fish species. Additionally, the role of IgT as a teleost immunoglobulin is also underway as a targeted research endeavor for gut immunophysiology and mucosal immunity [61]. Cytokines associated with IgT regulation may enact undetermined components of mucosal immune response propagation, as the B-cell concentrations have been shown to be variable among teleost species [34].

Current and future research initiatives hold much promise for a more complete understanding of this immune system component. Many interesting findings have enveloped the more complex aspects of the adaptive immune processes with respect to systemic migration of immune cells and cytokines. A thorough understanding of the teleost intestinal immunology may provide some developmental comparisons for the mammalian immune system. Further investigation within this enteric system may also allow for enhanced vaccine delivery components, novel immunoprophylactic feedstuffs, and clarification of receptor interactions for defensive pathogen recognition.

\section{Teleost Cytokines}

Cytokines are signaling molecules and immunomodulating proteins that facilitate intercellular communication to aid immune response in both the innate and adaptive immune systems. These small proteins exert their effect on a variety of immune cells and have the ability to spread quickly throughout areas of inflammation, bacterial invasion, and viral entry. The conservation of cytokines across vertebrates is clear and many teleost studies incorporate the monitoring of cytokine expression as a measure of immune competency [62]. Alternatively, the genetic homology between related cytokines is dissimilar within families, which may account for their ability to encompass a large scope of pathogens and their physiological impacts [63]. The major families of cytokines are the ILs, Interferons (IFN), Tumor Necrosis Factors (TNF), and Transforming Growth Factors (TGF) [62]. These proteins are produced by a number of immune cells, including lymphocytes, granulocytes, and macrophages, again spanning innate and adaptive teleost immunity [64]. Each of these subset members exerts their effect 
in a regulatory manner and may affect the progressive activities of both viral and bacterial removal. The TNF-A cytokine is one of the preliminary cytokines released following a malignant instigation and it contains the ability to induce future interleukins [62]. The TNF superfamily contains approximately 19 protein constituents and they are responsible for inducing immune cell relocation, apoptosis, and leukocyte differentiation [65]. TNF-A has been found to initiate macrophages to the inflammatory site, command neutrophil migration, and heighten the respiratory burst potential [66]. The next phase in cytokine solicitation may be the interleukin modulation. The interleukins are also responsible for bathing the infectious areas with granulocytes and macrophages while further secreting additional cytokines to cleanse the region. There have been approximately 35 families of interleukins identified to date and many of these cytokines are secreted by T-helper cells, macrophages, monocytes, and endothelial borders [67]. The IL-B homologue has been detected in 13 teleost species and has been found to exhibit a conserved function of macrophage migration and $\mathrm{T}$ cell recruitment for advanced viral pathogens [14] [68]. COX-2 is a pro-inflammatory gene that is also stimulated by IL-1B and aids in the expression of MHC class II macrophages [62]. Following further macrophage recruitment, the interleukins also contain the ability to activate cortisol release via the hypothalamic-pituitaryinterrenal axis to alleviate symptoms associated with the infection [66]. IL-B and IL-A are often first to be produced as a result of infection and may further propagate interleukin production for enhanced specificity to the inflammation [63]. Conversely, viral infections are often slated to IL-18 expression for the incorporation of IFNs and T-helper cell conscription [63]. In addition, IL-4 is found to be an efficient promoter of Th2 differentiation while IL-2 stimulates the replication of $\mathrm{T}$ cells after an antigen has been presented to the adaptive system [62].

IFNs are involved in multiple phases of the immune system, but mainly target the viral entry. There are two classes of interferons, Type I and Type II molecules, that produce various immunological responses [69]. Type I IFNs are produced by various immune cells following viral stimulation and are generally classified as being $\alpha$ or $\beta$ [69]. Type II IFNs are elicited by T cells and NK cell types to enhance phagocytosis from macrophages and increased MHC I and II production [63]. This type is also referred to as the IFN- $\gamma$ and this cytokine is summoned by increased concentrations of IL-12 and IL-18 [69]. In the case of many hormones, IFNs act by attaching to a specific receptor and they are mediated by regulatory factors, including the protein family Suppressors of Cytokine Activity (SOCS) [70]. The SOCS proteins target the Janus kinase/signal transducers and activators of transcription (JAK-STAT) pathway, which adjusts cellular functions based on cellular conditions and external stimuli [71]. SOCS-1 and SOCS-3 act upon this JAK-STAT pathway to control various concentrations of system cytokines, thus eliminating inflammation and tissue damage that may occur with increased cytokine expression [71]. As a result of this regulatory mechanism, it is clear that negative feedback for the SOCS proteins is crucial to proper functioning of teleost immune systems, in addition to proper cytokine 
production. Aside from the negative inhibition, certain PAMPs, bacteria, viruses, and parasites have demonstrated the ability to induce SOCS expression [72]. Furthermore, the teleost stress response, more specifically the release of cortisol, has been found to up-regulate the expression of the SOCS genes and create an inhibition of the regulatory cytokines [73]. The discovery of SOCS proteins and their genetic constituents within yellow perch (Perca flavescens) was only recently discovered by Shepherd et al. [71]. The expression mapping associated with these genes alludes to the complexity of cytokine regulation within teleost immune responses.

Recombination-activating gene 1 (RAG-1) is an essential component of the antigen-dependent reorganization of antibodies in the adaptive immune response of teleosts [74]. In the adaptive immune response, the antibody components rearrange their genetic structure to associate with their respective antigen components, thus allowing for efficient clearance. The RAG-1 is effective with developing $\mathrm{B}$ and $\mathrm{T}$ cell and its expression is aligned with the developmental immune stages in fishes [75]. As such, RAG-1 expression may be used as a marker for studying the ontogeny of the teleost immune system through somatic growth stages. In a study of RAG-1 mutation in zebrafish, it was determined that reduced RAG-1 expression led to a down-regulation of adaptive immune cells (non-functional lymphocytes, NK cells, etc.) while neutrophil concentrations increased in a compensatory response [76]. There is only a single copy of RAG-1 available in the genome for expression; therefore, any genetic mutations during transcription of the gene may also result in immunodeficiency for the fish. RAG-1 is regulated by IKAROS, a nuclear protein, to direct appropriate antibody reception sites for the $\mathrm{B}$ cell population [77]. Hence, the antibody determining regions of lymphocytes is organized in a complex manner and controlled by cytokines or genetic regulation at various organizational levels.

Cytokines derived from the TGF superfamily serve as modulators of lymphocyte availability and function while directing the activity of many other immune cells via chemotaxis [65]. Differentiation of both lymphocytes and $\mathrm{T}$ cells are dictated by TGF- $\beta$ levels and the molecule may play a role in reproduction or apoptosis of these immune cells [26]. By the same token, TGF- $\beta$ ensures appropriate levels of the adaptive immune molecules to prevent excessive proliferation and adequate availability in the case of infectious onset. TGF- $\beta$ has also been found to play an important role in intestinal immune regulation and may be essential to avoiding intestinal enteritis with many soybean-based products [78]. In short, the vast realm of cytokine signaling is imperative for the proper functioning of the teleost immune system. Further examination of cytokine expression provides researchers with relevant information towards immune system ontogeny, pathological signaling, and the administration of immunostimulants to provide benefits for fish.

\section{Immunoprophylactics}

Fish that have well-developed, highly functioning immune systems provide in- 
creased aquaculture yields. Hence, the evaluation of immune-enhancing ingredients in aquaculture applications has been a research subject of increasing interest in the past few decades. Many novel feed additives and administration methods have been studied to improve fish health. Traditionally, non-specific immune parameters have been studied in teleosts as injection was the most common administration route, and thus, response times were limited to shorter durations following treatment [5]. Injection may induce a fast-acting response, but may require repeat dosages that cause stress. The route of administration is an integral component to immunostimulant testing. Recently, immunostimulants have been incorporated into aquafeeds for oral delivery, therefore creating an extension of the immunoprophylactic efficiency [79]. Oral (feed) administration alleviates the stressful injections, but estimation and control of dosage is difficult, as the medication may have to be applied in an unpalatable vector. This delivery method is most practical for enhanced dietary blends that may serve as potent disease-resisting supplements. The combination of the immunostimulant offers the possibility of an easily digestible immunoprophylactic combined with a well-fitted dietary blend, thus ensuring appropriate dispensing and ensuring a regimen that may have long-term potential (dependent upon feeding schedules). Common immunostimulants are derivatives from bacteria and yeasts. Various microbial fermentation processes have also appeared in the plant-based feedstuffs market, thereby creating a need for immunoprophylactic testing to determine efficacy. The evaluation of these enhanced dietary blends may clarify and identify important immune-enhancing properties that could alleviate expensive treatments or medications.

Previous studies with injected microbial components have elicited improvements to the innate immune system, including lysozyme production, increased complement activation, and have promoted macrophage function [5]. Components from bacterial cell walls and internal structures act by heightening availability of non-specific cellular components and raising antibody titers [79]. Lipopolysaccharides (LPS), peptidoglycan components (PG), and Mycobacterium strains have all been previously implemented to heighten immune response in teleosts [80]. The responses generated as a result of these treatments have been increased phagocytosis, respiratory burst, and $\mathrm{T}$ cell and $\mathrm{B}$ cell up-regulation. For example, Casadei et al. found that the feeding of PGs to rainbow trout increased levels of antimicrobial peptides (AMPs), such as cathelicidin-land $\beta$ defensin 4, produced over a 14-day time interval [81]. The transcription of AMP mRNA is increased following bacterial injection, therefore creating an overconcentrated pool of available AMPs to combat infection and maintain an elevated presence [82]. This ability to up-regulate AMP expression is linked to the ability to recognize PAMPs on the bacterial components. The PG in the Casadei study was isolated from bacterial sources, similar to the extraction of many immunostimulants from bacterial, plant, and viral sources [81]. This extraction process from bacteria may be an efficient means of generating heightened immunity, but may prove too costly on a production scale. Consequently, many 
researchers have turned to more naturally abundant yeast or plant sources for their immunogenic properties.

Polysaccharide-derived immunostimulants have been favored for their ability to be transferred orally and their capacity to be incorporated directly into aquafeeds. $\beta$-glucans have emerged as a frontrunner in many teleost studies because of their availability for processing and capacity to enhance the immune system [5]. $\beta$-glucans are found in the cell walls of yeast and fungi with inherent $\beta$-1,3 and $\beta-1,6$ glycosidic linkages [83]. Innate immune cells in teleosts have been found to have specific glucan receptors on the cell membranes that appear to stimulate phagocytic ability [84]. Thus, a dosage-dependent concentration of $\beta$-glucans may be optimized for immune enhancement. Furthermore, similar glucan forms are also found in the fibrous components of oats and barley, which are commonly used in agricultural feeds [80]. The inclusion of these feed ingredients in conjunction with bioprocessing may create new variations of immunoprophylactic feedstuffs. In a capacity similar to bacterial injection, the $\beta$-glucan is responsible for increasing macrophage activity, respiratory burst, and cytokine production [85]. Therefore, it appears that many of the innate immune parameters are modulated with the specialized feeds. Although many of the $\beta$-glucan teleost studies target innate immune responses, some adaptive immune characteristics have also warranted investigation.

Cell-mediated immunity components and cytokine dynamics may change depending on administration route, concentration of glucan administered, and teleost species. For example, Chansue et al. found a slightly increased array of cytokine expressions in Nile tilapia following oral dosages of $\beta$-glucans [86]. IL$\beta$ and TNF were evaluated using anti-human cytokine protein components and ELISA; both hormones are known for their interactions with T and B lymphocytes. Conversely, Rodriguez et al. determined that injection with $\beta$-glucans in zebrafish resulted in much more elevated IL- $\beta$ and TNF levels [87]. These authors suggest that the immune induction of $\beta$-glucans may up-regulate transcription in particular regions, creating the promotion of possible cytokine variations (e.g. TNF- $\alpha 1$ and TNF- $\alpha 2$ ) with different effector functions. This variation may be further examined in a variety of fish species. Adjusting the glucan concentration and induction schedule may produce optimized applications for individual species and life stages.

There have also been recent accounts of immunogenic properties of soybean meal in various aquaculture species. An investigation with Atlantic salmon and soybean meal dietary supplementation has yielded supporting evidence for immune enhancement [88] [89]. Following administration of soy diets, the salmon were found to have increased concentrations of macrophages within the lamina propria of the distal intestine [88] [89]. There has been much debate whether soybean-based feeds have a beneficial or negative impact on the immune system, as some soybean-based diets may induce higher than normal immunoglobulin levels while limiting leukocyte recruitment numbers to respond to the pathogen. The predominant form of enteritis resulting from soybean feeds may create en- 
hanced susceptibility for opportune infections, such as furunculosis, caused by Aeromonas salmonicida. Alternatively, it has been observed that macrophage chemotaxis and antibody titers have been found to increase with the increasing levels of soybean-based protein within the aquaculture diets [90]. This increase may be attributed to less than adequate amino acid levels in the feeds, namely arginine, glutamine, and cysteine. Although fishmeal contains a relatively comprehensive amino acid profile, the enhanced soybean-based diets may offer larger inclusions of these immune-stimulating amino acids while promoting a more proficient digestibility for nutrient absorption and growth.

Nucleotide supplementation has also been found to elicit an immunomodulation response on some teleost species. The addition of nucleotides has been of recent interest and has been implemented to assist with enhanced growth in soybean diets. Nucleotide addition refers to the process of adding genetic constituents in the effort to provide more strata for somatic growth and development. More specifically, nucleotide addition has been found to enhance cytokine expression levels, assist with development of the GIT, and promote an increase in fillet mass within some species [91]. It has also been found that appropriate nucleotide profiles are directly correlated with increased cytokine levels and gene expression of IL- $1 \beta$ and IgM throughout the kidneys [74]. These benefits may be of importance in soybean diets as they can compensate for some nutritional shortcomings while creating a possible immunoprophylactic effect.

Immunostimulant testing most certainly warrants further investigation and quantification for exact efficacies. As feed manufacturers move to bioprocessed plant-based feed ingredients, immunostimulant testing may reveal hidden health benefits that may improve aquaculture production.

\section{Concluding Remarks}

With respect to the fish immune response and topics presented within this review, the overall process may be characterized within the general teleost immune response directives (Figure 1). Although many specific components of the teleost immune response may be a focal part of research, a more comprehensive understanding of the interactions and combined efforts of system branches presents. For instance, current research efforts aim to further investigate the role of mucosal immunity in teleost fish and characterize the immunopotentiating interactions with the gut microbiome [92]. Further, this systemic understanding has many applications for oral vaccination design and the development of protective responses within the fish [93] [94]. The future development and improved efficiency of immune-enhancing feedstuffs and disease management strategies should promote more superior yields and increase the sustainability of intensive aquaculture.

\section{Acknowledgements}

This effort was supported in part by the South Dakota Soybean Research and Promotion Council and the South Dakota Agriculture Experiment Station. 


\section{References}

[1] Tidwell, J.H. and Allan, G.L. (2001) Fish as Food: Aquaculture's Contribution. EMBO Reports, 2, 958-963. https://doi.org/10.1093/embo-reports/kve236

[2] FAO (2016) The State of World Fisheries and Aquaculture 2016. Rome, Italy.

[3] World Bank Group (2014) Reducing Disease Risk in Aquaculture. World Bank Report Number 88257-GLB, June 2014.

[4] Dixon, B. (2012) Vaccines for Finfish Aquaculture: What Do We Need to Know to Make Them Work? Electronic Journal of Biotechnology, 15, 1-9. https://doi.org/10.2225/vol15-issue5-fulltext-18

[5] Sakai, M. (1999) Current Status of Fish Immunostimulants. Aquaculture, 172, 63 92.

[6] Oliva-Teles, A. (2012) Nutrition and Health of Aquaculture Fish. Journal of Fish Diseases, 35, 83-108. https://doi.org/10.1111/j.1365-2761.2011.01333.x

[7] Yada, T. (2007) Growth Hormone and Fish Immune System. General and Comparative Endocrinology, 152, 353-358. https://doi.org/10.1016/j.ygcen.2007.01.045

[8] Magnadottir, B. (2006) Innate Immunity of Fish (Overview). Fish and Shellfish Immunology, 20, 137-151.

[9] Esteban, M.A. (2012) An Overview of the Immunological Defenses in Fish Skin. ISRN Immunology, 2012, Article ID: 853470. https://doi.org/10.5402/2012/853470

[10] Balasubramanian, S., Baby Rani, P., Arul Prakash, A., Prakash, M., Senthilraja, P. and Gunasekaran, G. (2012) Antimicrobial Properties of Skin Mucus from Four Freshwater Cultivable Fishes (Catla catla, Hypophthalmichthys, Labeo rohita and Ctenopharyngodon idella). African Journal of Microbiology Research, 6, 5110-5120.

[11] Ellis, A.E. (2001) Innate Host Defense Mechanisms of Fish against Viruses and Bacteria. Developmental and Comparative Immunology, 25, 827-39.

[12] Austin, B. and McIntosh, D. (1988) Natural Antibacterial Compounds on the Surface of Rainbow Trout, Salmo gairdneri Richardson. Journal of Fish Diseases, 11, 275-277. https://doi.org/10.1111/j.1365-2761.1988.tb00550.x

[13] Ewart, K. (2001) Lectins of the Innate Immune System and Their Relevance to Fish Health. ICES Journal of Marine Science, 58, 380-385. https://doi.org/10.1006/jmsc.2000.1020

[14] Whyte, S.K. (2007) The Innate Immune Response of Finfish-A Review of Current Knowledge. Fish and Shellfish Immunology, 23, 1127-1151.

[15] Paulsen, S.M., Engstad, R.E. and Robertsen, B. (2001) Enhanced Lysozyme Production in Atlantic Salmon (Salmo salar L.) Macrophages Treated with Yeast BetaGlucan and Bacterial Lipopolysaccharide. Fish and Shellfish Immunology, 11, 2337.

[16] Uribe, C., Folch, H., Enriquez, R. and Moran, G. (2011) Innate and Adaptive Immunity in Teleost Fish: A Review. Veterinarni Medicina, 56, 486-503.

[17] Demers, N.E. and Bayne, C.J. (1997) The Immediate Effects of Stress on Hormones and Plasma Lysozyme in Rainbow Trout. Developmental and Comparative Immunology, 21, 363-373.

[18] Crippen, T.L., Bootland, L.M., Leong, J.C., Fitzpatrick, M.S, Schreck, C.B. and Vella, A.T. (2001) Analysis of Salmonid Leukocytes Purified by Hypotonic Lysis of Erythrocytes. Journal of Aquatic Animal Health, 13, 234-245. https://doi.org/10.1577/1548-8667(2001)013<0234:AOSLPB>2.0.CO;2

[19] Sepulcre, M.P., Pelegrin, P., Mulero, V. and Meseguer, J. (2002) Characterization of 
Gilthead Seabream Acidophilic Granulocytes by a Monoclonal Antibody Unequivocally Points to Their Involvement in Fish Phagocytic Response. Cell and Tissue Research, 308, 97-102. https://doi.org/10.1007/s00441-002-0531-1

[20] Belosevic, M., Haddad, G., Walsh, J., Grayfer, L., Katzenback, B.A., Hanington, P.C., Neumann, N.F. and Stafford, J.L. (2009) Innate Immunity of Fish: Antimicrobial Responses of Fish Macrophages. In: Zaccone, G., Meseguer, J., Garcia-Ayala, A. and Kapoor, B.G., Eds., Fish Defenses. Immunology, Science Publishers, New Hampshire, USA, 145-184. https://doi.org/10.1201/b10188-6

[21] Buonocore, F., Forlenza, M., Randelli, E., Benedetti, S., Bossu, P., Meloni, S., et al. (2005) Biological Activity of Sea Bass (Dicentrarchus labrax L.) Recombinant Interleukin-1 Beta. Marine Biotechnology, 7, 609-617. https://doi.org/10.1007/s10126-004-5131-5

[22] Miller, N., Wilson, M., Bengten, E., Stuge, T., Warr, G. and Clem, W. (1998) Functional and Molecular Characterization of Teleost Leukocytes. Immunological Reviews, 166, 187-197. https://doi.org/10.1111/j.1600-065X.1998.tb01263.x

[23] Sato, A., Mayer, W.E., Overath, P. and Klein, J. (2003) Genes Encoding Putative Natural Killer Cell C-Type Lectin Receptors in Teleostean Fishes. Proceedings of the National Academy of Sciences of the United States of America, 100, 7779-7784. https://doi.org/10.1073/pnas.1235938100

[24] Magor, B.G. and Magor, K.E. (2001) Evolution of Effectors and Receptors of Innate Immunity. Developmental and Comparative Immunology, 25, 651-682.

[25] Boshra, H., Li, J. and Sunyer, J.O. (2006) Recent Advances on the Complement System of Teleost Fish. Fish and Shellfish Immunology, 20, 239-262.

[26] Zhu, L.Y., Nie, L., Zhu, G., Xiang, L.X. and Shao, J.Z. (2013) Advances in Research of Fish Immune-Relevant Genes: A Comparative Overview of Innate and Adaptive Immunity in Teleosts. Developmental and Comparative Immunology, 39, 39-62.

[27] Bayne, C.J. and Gerwick, L. (2001) The Acute Phase Response and Innate Immunity of Fish. Developmental and Comparative Immunology, 25, 725-743.

[28] Nakao, M., Tsujikura, M., Ichiki, S., Vo, T.K. and Somamoto, T. (2011) The Complement System in Teleost Fish: Progress of Post-Homolog-Hunting Researches. Developmental and Comparative Immunology, 35, 1296-1308.

[29] Tort, L., Balasch, J.C. and Mackenzie, S. (2003) Fish Immune System. A Crossroads between Innate and Adaptive Responses. Immunologia, 22, 277-286.

[30] Scapigliati, G., Meloni, S., Buonocore, F., Boss, P., Prugnoli, D. and Secombes, C.J. (2003) Immunopurification of B Lymphocytes from Sea Bass Dicentrarchus labrax (L.). Marine Biotechnology, 5, 214-221. https://doi.org/10.1007/s10126-002-0100-3

[31] Kaatari, S., Brown, G., Kaattari, I., Ye, J., Haines, A. and Bromage, E. (2009) The Cellular and Developmental Biology of the Teleost Antibody Response. In: Zaccone, G., Meseguer, J., Garcia-Ayala, A. and Kapoor, B.G., Eds., Fish Defenses: Immunology, Science Publishers, New Hampshire, USA, 75-129. https://doi.org/10.1201/b10188-4

[32] Danilova, N. and Steiner, L.A. (2002) B Cells Develop in the Zebrafish Pancreas. Proceedings of the National Academy of Sciences of the United States of America, 99, 13711-13716. https://doi.org/10.1073/pnas.212515999

[33] Hansen, J.D., Landis, E.D. and Phillips, R.B. (2005) Discovery of a Unique Ig Heavy-Chain Isotype (IgT) in Rainbow Trout: Implications for a Distinctive B Cell Developmental Pathway in Teleost Fish. Proceedings of the National Academy of Sciences of the United States of America, 102, 6919-6924.

https://doi.org/10.1073/pnas.0500027102 
[34] Salinas, I., Zhang, Y.-A. and Sunyer, J.O. (2011) Mucosal Immunoglobulins and B cells of Teleost Fish. Developmental and Comparative Immunology, 35, 1346-1365.

[35] Savan, R. and Sakai, M. (2009) Immunoglobulin Genes of Teleosts: Discovery of New Immunoglobulin Class. In: Zaccone, G., Meseguer, J., Garcia-Ayala, A. and Kapoor, B.G., Eds., Fish Defenses. Immunology, Science Publishers, New Hampshire, USA, 221-239. https://doi.org/10.1201/b10188-8

[36] Edholm, E.-S., Bengten, E. and Wilson, M. (2011) Insights into the Function of IgD. Developmental and Comparative Immunology, 35, 1309-1316.

[37] Hikima, J., Jung, T.S. and Aoki, T. (2011) Immunoglobulin Genes and Their Transcriptional Control in Teleosts. Developmental and Comparative Immunology, 35, 924-936.

[38] Castro, R., Bernard, D., Lefranc, M.P., Six, A., Benmansour, A. and Boudinot, P. (2011) T Cell Diversity and TcR Repertoires in Teleost Fish. Fish and Shellfish Immunology, 31, 644-654.

[39] Gerard, A., Khan, O., Beemiller, P., Oswald, E., Hu, J., Matloubian, M., et al. (2013) Secondary T Cell Synaptic Interactions Drive the Differentiation of Protective CD ${ }^{+}$ T Cells. Nature Immunology, 14, 356-363. https://doi.org/10.1038/ni.2547

[40] Boschi, I., Randelli, E., Buonocore, F., Casani, D., Bernini, C., Fausto, A.M., et al. (2011) Transcription of T Cell-Related Genes in Teleost Fish, and the European Sea Bass (Dicentrarchus labrax) as a Model. Fish and Shellfish Immunology, 31, 655662.

[41] Yamaguchi, T., Katakura, F., Someya, K., Dijkstra, J.M., Moritomo, T. and Nakanishi, T. (2013) Clonal Growth of Carp (Cyprinus carpio) T Cells in Vitro: LongTerm Proliferation of Th2-Like Cells. Fish and Shellfish Immunology, 34, 433-442.

[42] Koppang, E.O., Fischer, U., Moore, L., Tranulis, M.A., Dijkstra, J.M., Kollner, B., et al. (2010) Salmonid T Cells Assemble in the Thymus, Spleen and in Novel Interbranchial Lymphoid Tissue. Journal of Anatomy, 217, 728-739. https://doi.org/10.1111/j.1469-7580.2010.01305.x

[43] Boudinot, P., Boubeker, S. and Benmansour, A. (2001) Rhabidovirus Infection Induces Public and Private T Cell Responses in Teleost Fish. The Journal of Immunology, 167, 6202-6209. https://doi.org/10.4049/jimmunol.167.11.6202

[44] Rombout, J.H., Abelli, L., Picchietti, S., Scapigliati, G. and Kiron, V. (2011) Teleost Intestinal Immunology. Fish and Shellfish Immunology, 31, 616-626.

[45] Martin, E., Verlhac-Trichet, V., Legrand-Frossi, C. and Frippiat, J.P. (2012) Comparison between Intestinal and Non-Mucosal Immune Functions of Rainbow Trout, Oncorhynchus mykiss. Fish and Shellfish Immunology, 33, 1258-1268.

[46] Sales, J. (2009) The Effect of Fish Meal Replacement by Soybean Products on Fish Growth: A Meta-Analysis. British Journal of Nutrition, 102, 1709-1722. https://doi.org/10.1017/S0007114509991279

[47] Romarheim, O.H., Zhang, C. Penn, M., Liu, Y.J., Tian, L.X., Skrede, A., et al. (2008) Growth and Intestinal Morphology in Cobia (Rachycentron canadum) Fed Extruded Diets with Two Types of Soybean Meal Partly Replacing Fish Meal. Aquaculture Nutrition, 14, 174-180. https://doi.org/10.1111/j.1365-2095.2007.00517.x

[48] Sahlmann, C., Sutherland, B.J., Kortner, T.M., Koop, B.F., Krogdahl, A. and Bakke, A.M. (2013) Early Response of Gene Expression in the Distal Intestine of Atlantic Salmon (Salmo salar L.) during the Development of Soybean Meal Induced Enteritis. Fish and Shellfish Immunology, 34, 599-609.

[49] Urn, P.A., Schrama, J.W., Rombout, J.H.W.M., Obach, A., Jensen, L., Koppe, W., et al. (2008) Soybean Meal-Induced Enteritis in Atlantic Salmon (Salmo salar L.) at 
Different Temperatures. Aquaculture Nutrition, 14, 324-330. https://doi.org/10.1111/j.1365-2095.2007.00534.x

[50] Torrecillas, S., Makol, A., Betancor, M.B., Montero, D., Caballero, M.J., Sweetman, J., et al. (2013) Enhanced Intestinal Epithelial Barrier Health Status on European Sea Bass (Dicentrarchus labrax) Fed Mannan Oligosaccharides. Fish and Shellfish Immunology, 34, 1485-1495.

[51] Abelli, L., Picchietti, S., Romano, N., Mastrolia, L. and Scapigliati, G. (1997) Immunohistochemistry of Gut-Associated Lymphoid Tissue of the Sea Bass Dicentrarchus labrax (L.). Fish and Shellfish Immunology, 7, 235-245.

[52] Nayak, S.K. (2010) Probiotics and Immunity: A Fish Perspective. Fish and Shellfish Immunology, 29, 2-14.

[53] Nayak, S.K. (2010) Role of Gastrointestinal Microbiota in Fish. Aquaculture Research, 41, 1553-1573. https://doi.org/10.1111/j.1365-2109.2010.02546.x

[54] Fournier-Betz, V., Quentel, C., Lamour, F. and Leven, A. (2000) Immunocytochemical Detection of Ig-Positive Cells in Blood, Lymphoid Organs and the Gut Associated Lymphoid Tissue of the Turbot (Scophthalmus maximus). Fish and Shellfish Immunology, 10, 187-202.

[55] Picchietti, S., Guerra, L., Bertoni, F., Randelli, E., Belardinelli, M.C. and Buonocore, F. (2011) Intestinal T Cells of Dicentrarchus labrax (L.): Gene Expression and Functional Studies. Fish and Shellfish Immunology, 30, 609-617.

[56] Dezfuli, B.S., Giovinazzo, G., Lui, A. and Giari, L. (2008) Inflammatory Response to Dentitruncus truttae (Acanthocephala) in the Intestine of Brown Trout. Fish and Shellfish Immunology, 24, 726-733.

[57] Inami, M., Taverne-Thiele, A.J., Schroder, M.B., Kiron, V. and Rombout, J.H. (2009) Immunological Differences in Intestine and Rectum of Atlantic Cod (Gadus morhua L.). Fish and Shellfish Immunology, 26, 751-759.

[58] Fuglem, B., Jirillo, E., Bjerkas, I., Kiyono, H., Nochi, T., Yuki, Y., et al. (2010) Antigen Sampling Cells in the Salmonid Intestinal Epithelium. Developmental and Comparative Immunology, 34, 768-774.

[59] Mulder, I.E., Wadsworth, S. and Secombes, C.J. (2007) Cytokine Expression in the Intestine of Rainbow Trout (Oncorhynchus mykiss) during Infection with Aeromonas salmonicida. Fish and Shellfish Immunology, 23, 747-759.

[60] Ordas, M.C., Castro, R., Dixon, B., Sunyer, J.O., Bjork, S., Bartholomew, J., Korytar, T., Kollner, B., Cuesta, A. and Tafalla, C. (2012) Identification of a Novel CCR7 Gene in Rainbow Trout with Differential Expression in the Context of Mucosal or Systemic Infection. Developmental and Comparative Immunology, 38, 302-311.

[61] Zhang, Y.A., Salinas, I., Li, J., Parra, D., Bjork, S., Xu, Z., LaPatra, S.E., Bartholomew, J. and Sunyer, J.O. (2010) IgT, a Primitive Immunoglobulin Class Specialized in Mucosal Immunity. Nature Immunology, 11, 827-835. https://doi.org/10.1038/ni.1913

[62] Secombes, C.J., Zou, J. and Bird, S. (2009) Fish Cytokines: Discovery, Activities and Potential Applications. In: Zaccone, G., Meseguer, J., Garcia-Ayala, A. and Kapoor, B.G., Eds., Fish Defenses. Immunology, Science Publishers, New Hampshire, USA, 1-36. https://doi.org/10.1201/b10188-2

[63] Huising, M.O., Stet, R.J., Savelkoul, H.F. and Verburg-van Kemenade, B.M. (2004) The Molecular Evolution of the Interleukin-1 Family of Cytokines; IL-18 in Teleost Fish. Developmental and Comparative Immunology, 28, 395-413.

[64] Savan, R. and Sakai, M. (2006) Genomics of Fish Cytokines. Comparative Biochemistry and Physiology Part D: Genomics and Proteomics, 1, 89-101. 
[65] Garcia-Ayala, A. and Chaves-Pozo, E. (2009) Leukocytes and Cytokines Present in Fish Testes. In: Zaccone, G., Meseguer, J., Garcia-Ayala, A. and Kapoor, B.G., Eds., Fish Defenses. Immunology, Science Publishers, New Hampshire, USA, 37-74. https://doi.org/10.1201/b10188-3

[66] Kvamme, B.O., Gadan, K., Finne-Fridell, F., Niklasson, L., Sundh, H., Sundell, K., Taranger, G.L. and Evensen, O. (2013) Modulation of Innate Immune Responses in Atlantic Salmon by Chronic Hypoxia-Induced Stress. Fish and Shellfish Immunology, 34, 55-65.

[67] Secombes, C.J., Wang, T. and Bird, S. (2011) The Interleukins of Fish. Developmental and Comparative Immunology, 35, 1336-1345.

[68] Mathew, J.A., Guo, Y.X., Goh, K.P., Chan, J., Verburg-van Kemenade, B.M.L and Kwang, J. (2002) Characterisation of a Monoclonal Antibody to Carp IL-1 $\beta$ and the Development of a Sensitive Capture ELISA. Fish and Shellfish Immunology, 13, 85-95.

[69] Robertsen, B. (2006) The Interferon System of Teleost Fish. Fish and Shellfish Immunology, 20, 172-191.

[70] Zou, J. and Secombes, C.J. (2011) Teleost Fish Interferons and Their Role in Immunity. Developmental and Comparative Immunology, 35, 1376-1387.

[71] Shepherd, B.S., Rees, C.B., Binkowski, F.P. and Goetz, F.W. (2012) Characterization and Evaluation of Sex-Specific Expression of Suppressors of Cytokine Signaling (SOCS)-1 and -3 in Juvenile Yellow Perch (Perca flavescens) Treated with Lipopolysaccharide. Fish and Shellfish Immunology, 33, 468-481.

[72] Wang, T., Gorgoglione, B., Maehr, T., Holland, J.W., Vecino, J.L., Wadsworth, S., et al. (2011) Fish Suppressors of Cytokine Signaling (SOCS): Gene Discovery, Modulation of Expression and Function. Journal of Signal Transduction, 2011, Article ID: 905813.

[73] Philip, A.M., Kim, D.S. and Vijayan, M.M. (2012) Cortisol Modulates the Expression of Cytokines and Suppressors of Cytokine Signaling (SOCS) in Rainbow Trout Hepatocytes. Developmental and Comparative Immunology, 38, 360-367.

[74] Low, C., Wadsworth, S., Burrells, C. and Secombes, C.J. (2003) Expression of Immune Genes in Turbot (Scophthalmus maximus) Fed a Nucleotide-Supplemented Diet. Aquaculture, 221, 23-40.

[75] Mao, M.G., Lei, J.L., Alex, P.M., Hong, W.S. and Wang, K.J. (2012) Characterization of RAG1 and IgM (mu Chain) Marking Development of the Immune System in Red-Spotted Grouper (Epinephelus akaara). Fish and Shellfish Immunology, 33, 725-735.

[76] Petrie-Hanson, L., Hohn, C. and Hanson, L. (2009) Characterization of RAG1 Mutant Zebrafish Leukocytes. BMC Immunology, 10, 8.

https://doi.org/10.1186/1471-2172-10-8

[77] Lin, J.H.-Y., Lin, H.-T., Lopez, C., Chen, T.-Y., Chen, M.-S. and Yang, H.-L. (2008) A Comparison of the Expression of Immunity-related Rag 1 and Ikaros Genes with Histogenesis of the Thymus in Epinephelus malabaricus (Bloch \& Schneider). Aquaculture Research, 39, 252-262. https://doi.org/10.1111/j.1365-2109.2007.01871.x

[78] Lilleeng, E.., Penn, M.H., Haugland, O., Xu, C., Bakke, A.M., Krogdahl, A., et al. (2009) Decreased Expression of TGF-Beta, GILT and T Cell Markers in the Early Stages of Soybean Enteropathy in Atlantic Salmon (Salmo salar L.). Fish and Shellfish Immunology, 27, 65-72.

[79] Gannam, A.L. and Schrock, R.M. (1999) Immunostimulants in Fish Diets. Journal of Applied Aquaculture, 9, 53-89. https://doi.org/10.1300/J028v09n04_06 
[80] Galeotti, M. (1998) Some Aspects of the Application of Immunostimulants and a Critical Review of Methods for their Evaluation. Journal of Applied Ichthyology, 14, 189-199. https://doi.org/10.1111/j.1439-0426.1998.tb00641.x

[81] Casadei, E., Bird, S., Vecino, J.L., Wadsworth, S. and Secombes, C.J. (2013) The Effect of Peptidoglycan Enriched Diets on Antimicrobial Peptide Gene Expression in Rainbow Trout (Oncorhynchus mykiss). Fish and Shellfish Immunology, 34, 529537.

[82] Smith, V. and Fernandes, J.M.O. (2009) Antimicrobial Peptides of the Innate Immune System. In: Zaccone, G., Meseguer, J., Garcia-Ayala, A. and Kapoor, B.G., Eds., Fish Defenses. Immunology, Science Publishers, New Hampshire, USA, 241 275. https://doi.org/10.1201/b10188-9

[83] Jorgensen, J.B. and Robertson, B. (1995) Yeast Beta-Glucan Stimulates Respiratory Burst Activityof Atlantic Salmon (Salmo salar L.) Macrophages. Developmental and Comparative Immunology, 19, 43-57.

[84] Palic, D., Andreasen, C.B., Herolt, D.M., Menzel, B.W. and Roth, J.A. (2006) Immunomodulatory Effects of Beta-Glucan on Neutrophil Function in Fathead Minnows (Pimephales promelas Rafinesque). Developmental and Comparative Immunology, 30, 817-830.

[85] Misra, C.K., Das, B.K., Mukherjee, S.C. and Pattnaik, P. (2006) Effect of Multiple Injections of Beta-Glucan on Non-Specific Immune Response and Disease Resistance in Labeo rohita Fingerlings. Fish and Shellfish Immunology, 20, 305-319.

[86] Chansue, N., Endo, M., Kono, T. and Sakai, M. (2000) The Stimulation of Cytokine-Like Proteins in Tilapia (Oreochromis niloticus) Orally Treated with Beta-1, 3-Glucan. Asian Fisheries Science, 13, 271-278.

[87] Rodriguez, I., Chamorro, R., Novoa, B. and Figueras, A. (2009) Beta-Glucan Administration Enhances Disease Resistance and Some Innate Immune Responses in Zebrafish (Danio rerio). Fish and Shellfish Immunology, 27, 369-373.

[88] Bakke-McKellep, A.M., Froystad, M.K., Lilleeng, E., Dapra, F., Refstie, S., Krogdahl, A. and Landsverk, T. (2007) Response to Soy: T Cell-Like Reactivity in the Intestine of Atlantic Salmon, Salmo salar L. Journal of Fish Diseases, 30, 13-25. https://doi.org/10.1111/j.1365-2761.2007.00769.x

[89] Bakke-McKellep, A.M., Press, C.M., Baeverfjord, G., Krogdahl, A. and Landsverk, T. (2000) Changes in Immune and Enzyme Histochemical Phenotypes of Cells in the Intestinal Mucosa of Atlantic Salmon, Salmo salar L., with Soybean Meal-Induced Enteritis. Journal of Fish Diseases, 23, 115-127. https://doi.org/10.1046/j.1365-2761.2000.00218.x

[90] Kiron, V. (2012) Fish Immune System and its Nutritional Modulation for Preventive Health Care. Animal Feed Science and Technology, 173, 111-133. https://doi.org/10.1016/j.anifeedsci.2011.12.015

[91] Li, P. and Gatlin, D.M. (2006) Nucleotide Nutrition in Fish: Current Knowledge and Future Applications. Aquaculture, 251, 141-152.

[92] Gomez, D., Sunyer, J.O. and Salinas, I. (2013) The Mucosal Immune System of Fish: The Evolution of Tolerating Commensals while Fighting Pathogens. Fish and Shellfish Immunology, 35, 1729-1739.

[93] Mutoloki, S., Munang'andu, H.M. and Evensen, Ø. (2015) Oral Vaccination of Fish -Antigen Preparations, Uptake, and Immune Induction. Frontiers in Immunology, 6, 519. https://doi.org/10.3389/fimmu.2015.00519

[94] Embregts, C.W. and Forlenza, M. (2016) Oral Vaccination of Fish: Lessons from Humans and Veterinary Species. Developmental and Comparative Immunology, 64, 118-137. 


\section{List of Abbreviations}

AMP: Antimicrobial peptide

ANF: Antinutritional factor

APC: Antigen presenting cell

ASC: Antibody secreting cells

B: Bursa-derived

BCR: B-cell receptor

$\mathrm{CD}$ : Cluster of differentiation

CD3: Complementarity-determining region 3

CRP: Complement reactive protein

ELISA: Enzyme-linked immunosorbent assay

GALT: Gut-associated lymphoid tissue

GIT: Gastrointestinal tract

IEL: Intra-epithelial lymphocyte

IFN: Interferon

IG: Immunoglobulin

IGF: Insulin-like growth factor

IL: Interleukin

JAK-STAT: Janus kinase/signal transducers and activators of transcription

LPS: Lipopolysaccharide

LT: Lymphotoxin

MAC: Membrane attack complex

MBL: Mannose binding lectin

MHC: Major histocompatibility complex

mRNA: Messenger ribonucleic acid

NK: Natural killer

PAMP: Pathogen-associated molecular pattern

PG: Peptidoglycan

PRR: Pattern recognition receptor

RAG: Recombination-activating gene

SAP: Serum amyloid protein

SOCS: Suppressor of cytokine signaling

T: Thymus

TCR: T-cell receptor

TGF: Transforming growth factor

Th: Helper T-cell

TNF: Tumor necrosis factor

USD: United States dollars 
Submit or recommend next manuscript to SCIRP and we will provide best service for you:

Accepting pre-submission inquiries through Email, Facebook, LinkedIn, Twitter, etc. A wide selection of journals (inclusive of 9 subjects, more than 200 journals)

Providing 24-hour high-quality service

User-friendly online submission system

Fair and swift peer-review system

Efficient typesetting and proofreading procedure

Display of the result of downloads and visits, as well as the number of cited articles Maximum dissemination of your research work

Submit your manuscript at: http://papersubmission.scirp.org/

Or contact ojas@scirp.org 